\title{
Continuous adiabatic industrial benzene nitration with mixed acid at a pilot plant scale
}

\author{
Paulo A. Quadros, Nuno M.C. Oliveira, Cristina M.S.G. Baptista* \\ Gepsi-PSE Group, Department of Chemical Engineering, University of Coimbra, Pólo II, Pinhal de Marrocos, 3030-290 Coimbra, Portugal
}

Received 22 July 2004; received in revised form 30 November 2004; accepted 7 December 2004

\begin{abstract}
A pilot plant for the continuous adiabatic nitration of benzene was constructed, reproducing the industrial operating conditions, in order to identify the reaction regime prevailing in this industrial process. Important process parameters were tested covering a wide range of operating conditions: reaction temperature $\left(80-135^{\circ} \mathrm{C}\right)$, benzene to nitric acid molar feed ratio (0.96-1.15) and stirring speed (390-1700 rpm). The residence time and the sulphuric acid strength were fixed at 2 min and $68 \%$, respectively. The data from a large number of experiments show a good agreement with the results of a mathematical model of the reactor.

In the range of operating conditions tested, it was shown that the prevailing reaction regime is the intermediate one $(0.3<H a<2)$. The film model used to predict the mononitrobenzene production according to the intermediate regime achieved a good accuracy. The asymptotic solutions for the fast and slow reaction regimes were compared with the full solution model and it was clearly shown that the last led to improved results. Since the film model is a simple approach to describe the mass transfer with simultaneous chemical reaction, the results achieved confirmed the adequacy of this modelling approach.
\end{abstract}

(c) 2004 Elsevier B.V. All rights reserved.

Keywords: Benzene nitration; Film model; Intermediate reaction regime; Liquid-liquid reaction; Heterogeneous reaction; Mass transfer

\section{Introduction}

Aromatic nitrations in mixed acid are one of the oldest processes performed in chemical industry, carried out since the 19 th century in batch or continuous reactors. However, these are heterogeneous reactions, where mass transfer processes and chemical reaction compete between themselves in a way that is yet not fully understood. These liquid-liquid reactions involve an organic phase dispersed in an aqueous one. The organic reactant (i.e., benzene or toluene) is transferred into the aqueous phase, also called mixed acid, where it reacts with the nitronium ion formed from the nitric acid. The sulphuric acid acts as a catalyst $[1,2]$. The strength of the sulphuric acid used determines the type of reaction developed, enabling operation

\footnotetext{
* Corresponding author. Tel.: +351 239 798700/38; fax: +351 239798703 .

E-mail addresses: quadros3@eq.uc.pt (P.A. Quadros), nuno@eq.uc.pt (N.M.C. Oliveira), cristina@eq.uc.pt (C.M.S.G. Baptista).
}

in the kinetic or the fast reaction regimes, if the remaining parameters are kept constant [3]. Important developments have been achieved in the comprehension of these heterogeneous reactions. Zaldivar and co-workers [4,5] used a batch reactor to study and model the toluene, benzene and clorobenzene nitration reactions with mixed acid in the slow and the fast reaction regimes. However, the study was carried out batch wise and the conditions used are very different from those in current industrial processes, namely the temperature and the reaction time. Several studies have been undertaken to clarify some aspects of these heterogeneous reactions, but they do not usually use industrial operating conditions; for easier experimental implementation they were carried out batch wise, at low temperature with high sulphuric acid strength, low nitric acid concentration and long reaction time. In the industry, at large scale, these processes are continuous, adiabatic, with a short residence time and carried out at high temperature.

A kinetic process study under continuous operation has some important advantages. At steady state, operating 


\begin{tabular}{|c|c|}
\hline \multicolumn{2}{|c|}{ Nomenclature } \\
\hline \multicolumn{2}{|c|}{ Notation } \\
\hline$a$ & effective interfacial area $\left(\mathrm{m}^{2} \mathrm{~m}^{-3}\right)$ \\
\hline$A l$ & Hinterland ratio \\
\hline$C_{i j}$ & $\begin{array}{l}\text { molar concentration of the compound } i \text { in the } \\
\text { stream } j\left(\mathrm{~mol} \mathrm{~m}^{-3}\right)\end{array}$ \\
\hline$D$ & diffusion coefficient $\left(\mathrm{m}^{2} \mathrm{~s}^{-1}\right)$ \\
\hline$D_{\mathrm{i}}$ & impeller diameter $(\mathrm{m})$ \\
\hline$E_{\mathrm{a}}$ & activation energy $\left(\mathrm{J} \mathrm{mol}^{-1}\right)$ \\
\hline$F_{i}$ & molar flow rate of compound $i\left(\mathrm{~mol} \mathrm{~s}^{-1}\right)$ \\
\hline $\mathrm{Ha}$ & Hatta number \\
\hline$J_{\mathrm{B}}$ & molar flux of benzene $\left(\mathrm{mol} \mathrm{m}^{-2} \mathrm{~s}^{-1}\right)$ \\
\hline$k$ & $\begin{array}{l}\text { first order or pseudo-first order reaction rate } \\
\text { constant }\left(\mathrm{s}^{-1}\right)\end{array}$ \\
\hline$k_{\mathrm{L}}$ & mass transfer coefficient $\left(\mathrm{m} \mathrm{s}^{-1}\right)$ \\
\hline$k_{\mathrm{O}}$ & pre-exponential factor $\left(\mathrm{m}^{3} \mathrm{~mol}^{-1} \mathrm{~s}^{-1}\right)$ \\
\hline$k_{2}$ & $\begin{array}{l}\text { second order reaction rate constan } \\
\left(\mathrm{m}^{3} \mathrm{~mol}^{-1} \mathrm{~s}^{-1}\right)\end{array}$ \\
\hline$k_{2 \text { obs }}$ & $\begin{array}{l}\text { second order observed reaction rate constant } \\
\left(\mathrm{m}^{3} \mathrm{~mol}^{-1} \mathrm{~s}^{-1}\right)\end{array}$ \\
\hline$m$ & partition coefficient \\
\hline$M_{i}$ & molecular weight of compound $i\left(\mathrm{~kg} \mathrm{~mol}^{-1}\right)$ \\
\hline MNB & mononitrobenzene \\
\hline & stirring speed $\left(\mathrm{s}^{-1}\right)$ \\
\hline$N$ & stirring speed (rpm) \\
\hline$P$ & power dissipated by the agitator $(\mathrm{W})$ \\
\hline$P_{\mathrm{o}}$ & power number \\
\hline$Q_{i}$ & volumetric flow rate of stream $i\left(\mathrm{~m}^{3} \mathrm{~s}^{-1}\right)$ \\
\hline$S$ & sulphuric acid weight fraction $(0-1)$ \\
\hline$T$ & temperature $(\mathrm{K})$ \\
\hline$V$ & reactor volume $\left(\mathrm{m}^{3}\right)$ \\
\hline$V_{\mathrm{b}}$ & $\begin{array}{l}\text { molar volume of benzene at its normal boiling } \\
\text { point }\left(\mathrm{m}^{3} \mathrm{~mol}^{-1}\right)\end{array}$ \\
\hline$V_{\mathrm{aq}}$ & volume of the continuous aqueous phase $\left(\mathrm{m}^{3}\right)$ \\
\hline$W e$ & Weber number, $\left(\left(n^{2} D_{i}^{3} \rho_{a q}\right) / \sigma\right)$ \\
\hline$x_{i}$ & mole fraction of compound $i$ \\
\hline$x$ & $\begin{array}{l}\text { space coordinate; distance from the interface } \\
(\mathrm{m})\end{array}$ \\
\hline \multicolumn{2}{|c|}{ Greek symbols } \\
\hline$\delta$ & thickness of the film (m) \\
\hline$\varepsilon$ & hold-up fraction of the organic phase \\
\hline$\varepsilon_{i}$ & hold-up fraction of the $i$ phase \\
\hline$\mu_{\mathrm{aq}}$ & viscosity of the aqueous phase (Pas) \\
\hline & density of the aqueous phase $\left(\mathrm{kg} \mathrm{m}^{-3}\right)$ \\
\hline$\sigma$ & interfacial tension $\left(\mathrm{N} \mathrm{m}^{-1}\right)$ \\
\hline \multicolumn{2}{|c|}{ Subscripts } \\
\hline $\mathrm{aq}$ & aqueous phase \\
\hline$b$ & bulk of aqueous phase \\
\hline
\end{tabular}

\begin{tabular}{|ll|}
\hline $\mathrm{B}$ & benzene \\
$\mathrm{f}$ & film of the aqueous phase \\
$\mathrm{N}$ & nitric acid \\
$\mathrm{S}$ & sulphuric acid \\
$\mathrm{W}$ & water \\
& \\
Superscripts \\
aq & aqueous phase \\
in & inlet of the reactor \\
org & organic phase \\
out & outlet of the reactor \\
& \\
\hline
\end{tabular}

conditions like temperature, phase composition and acid strength remain constant, helping to accurately quantify the reaction rate, the kinetic and the mass transfer parameters. In a batch wise operation these parameters are time dependent and, for instance, the formation of water during reaction has dual opposite impact: it causes a sulphuric acid dilution, which increases temperature but decreases catalyst strength. Another important feature is that, in continuous mode, large volume samples can be collected without interfering with the normal flow hydrodynamics in the reactor. Despite of this, only few studies were carried out under continuous operation conditions [6-8], since this operating mode requires more equipment, instrumentation and control and consumes more reactants, and therefore, has a higher cost.

In most industrial applications, the reaction regime prevailing in the nitration reaction is not known. The aim of this work is to clarify some important aspects of this heterogeneous system. The work developed uses a pilot plant reactor where the industrial operating conditions of a continuous adiabatic benzene nitration process were used, in order to better understand the phenomena involved in these mass transfer reaction processes.

\subsection{Mass transfer with chemical reaction}

Several studies have been undertaken in gas-liquid and liquid-liquid chemical reactions where at least one of the reactants has to transfer from another phase. Important contributions are reported in literature [9-11]. To identify the reaction regime in heterogeneous reactions the Hatta number $\mathrm{Ha}$ ) is used, which for a first or pseudo-first order reaction can be defined by [11]:

$H a=\frac{\sqrt{k D}}{k_{\mathrm{L}}}$

where $k$ is the reaction rate constant, $D$ is the diffusion coefficient of the diffusing specie and $k_{\mathrm{L}}$ is the mass transfer coefficient between phases. According to Chapman and Strachan [12] Eqs. (2) and (3), which are modifications of equations proposed by previous authors [13,3], can provide the diffusion coefficient of an aromatic compound in the mixed 
acid,

$D=\frac{7.4 \times 10^{-18}(\phi M)^{0.5} T}{V_{\mathrm{b}}^{0.6} \mu_{\mathrm{aq}}^{0.8}}$

$\phi M=2.6 x_{\mathrm{W}} M_{\mathrm{W}}+2.0 x_{\mathrm{S}} M_{\mathrm{S}}+1.05 x_{\mathrm{N}} M_{\mathrm{N}}$

where $x_{i}$ and $M_{i}$ are the mole fraction and the molecular weight of species $i$, respectively.

The mass transfer coefficient into the continuous aqueous phase, where the reaction takes place, can be calculated with Eq. (4) suggested in the sixties by Calderbank and MooYoung [14], which is still used in recent works on liquid dispersions [15]:

$k_{\mathrm{L}}=0.13\left[\left(\frac{P}{V_{\mathrm{aq}}}\right)\left(\frac{\mu_{\mathrm{aq}}}{\rho_{\mathrm{aq}}^{2}}\right)\right]^{1 / 4}\left[\frac{\mu_{\mathrm{aq}}}{\rho_{\mathrm{aq}} D}\right]^{-2 / 3}$

where $P$ is the power dissipated by the agitator and can be expressed as

$P=P_{\mathrm{o}} \rho_{\text {mixture }} n^{3} D_{\mathrm{i}}^{5}$,

where $P_{\mathrm{o}}$ is the power number. For a two-paddle impeller and in the range of Reynolds number used in this work, $P_{\mathrm{o}}$ is equal to 0.63 [16].

When $\mathrm{Ha}$ is less than 0.3 , the process is controlled by the chemical reaction rate and this is called the kinetic regime or slow reaction regime. If $\mathrm{Ha}$ is greater than 2, the chemical reaction is very fast and the diffusion resistances to mass transfer dominate the global heterogeneous reaction rate. In the intermediate regime both phenomena contribute and their influences cannot be dissociated. Since parameters like the kinetic constant and diffusion and mass transfer coefficients can be difficult to obtain, especially when the heterogeneous reactions are catalysed, as is the case of the aromatic nitrations, consensus on regime definitions is not always obtained. Most papers in literature study well-settled regimes like slow, fast or instantaneous regimes and avoid the intermediate regime as it is difficult to work in a region where the mass transfer and the chemical reaction compete between themselves $[4,5,17]$. Recently, Benbelkacem and Debellefontain [18] studied the intermediate regime using a gas-liquid reaction. To quantify the phenomena involved in these heterogeneous reactions the film model was used, despite being known as a simple representation of a complex phenomenon. Recent studies report good results with this model [4,5,17-19].

\subsection{Determination of the rate constant for the benzene nitration}

According to Olah et al. [2], in the nitration of aromatics, the reaction mechanism involves the formation of the nitronium ion, $\mathrm{NO}_{2}{ }^{+}$, and the extent of this dissociation can range from 0 to $100 \%$, depending on the mixed acid composition $[2,20,21]$. Thus, an appropriate mixed acid composition is crucial for establishing the reaction rate and the by-products formation $[22,23]$.

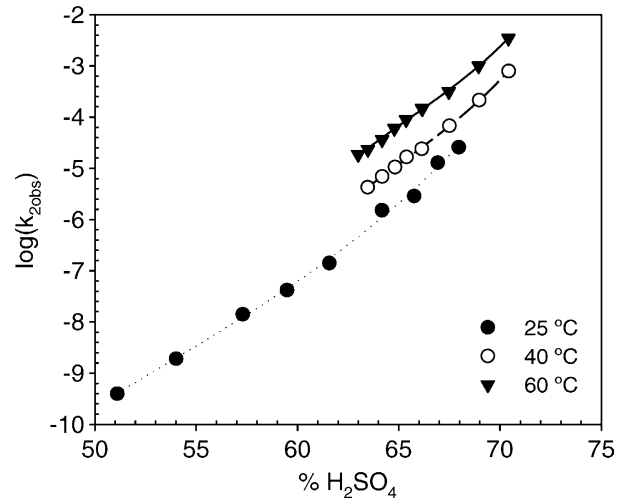

Fig. 1. Values of $\log k_{2 \mathrm{obs}}$ vs. sulphuric acid weight fraction. Data fitted from Deno and Stein [26] for $25^{\circ} \mathrm{C}$ and Marziano et al. [27] for 40 and $60^{\circ} \mathrm{C}$.

Several authors $[24,25]$ studied the nitration reaction of aromatic compounds like benzene and toluene with mixed acid and concluded it is a second order reaction. The nitronium ion concentration in Eq. (6) can be replaced by the nitric acid concentration, easier to measure, if the kinetic constant $\left(k_{2}\right)$ is replaced by the observed kinetic constant $\left(k_{2 \mathrm{obs}}\right)$. However, in the aqueous phase the nitric acid concentration is much higher than benzene, leading to a pseudo-first order reaction with a pseudo-first order kinetic constant $k$ :

$r=k_{2}[\mathrm{ArH}]\left[\mathrm{NO}_{2}{ }^{+}\right]=k_{2 \mathrm{obs}}[\mathrm{ArH}]\left[\mathrm{HNO}_{3}\right]=k[\mathrm{ArH}]$.

As the aromatic nitration is an acid catalysed reaction, the observed second order kinetic constant depends on the sulphuric acid strength and on the temperature [26,27]. The strong dependence of the observed kinetic constant on the sulphuric acid strength is registered in Fig. 1 where the $k_{2 \text { obs }}$ values obtained, at $25^{\circ} \mathrm{C}$ by Deno and Stein [26] and at 40 and $60^{\circ} \mathrm{C}$ by Marziano et al. [27], are plotted as function of the sulphuric acid weight concentration. A second order polynomial expression was used to fit these experimental data. For a given sulphuric acid strength these fits were used to calculate the $\ln \left(k_{2 \text { obs }}\right)$ for the three temperatures available and the Arrhenius' law was used to calculate the activation energy $\left(E_{\mathrm{a}}\right)$ and the pre-exponential factor $\left(k_{\mathrm{o}}\right)$ that depend only on the catalyst strength. In the range of interest for this work this procedure was repeated for different sulphuric acid strengths and the results were plotted in Fig. 2. The following equations correlate $E_{\mathrm{a}}$ and $k_{\mathrm{o}}$ to sulphuric acid weight fraction $S$ :

$$
\begin{aligned}
& E_{\mathrm{a}}=(-283.88 S+263.37) \times 1000 \\
& k_{\mathrm{o}}=\exp \left[166.64 S^{2}-254.36 S+113.79\right]
\end{aligned}
$$

The accuracy of this strategy is confirmed in Fig. 3 where the estimated values of $\log \left(k_{2 \mathrm{obs}}\right)$ are compared with the experimental results obtained by Deno and Stein [26] at $25^{\circ} \mathrm{C}$ and by Marziano et al. [27] at 40 and $60^{\circ} \mathrm{C}$. The relative error of the estimated values is below 5\%, for the data of Deno and Stein [26], and predictions with relative errors below 2\% were obtained for all experimental values of Marziano et al. [27], which confirm the validity of this method. 


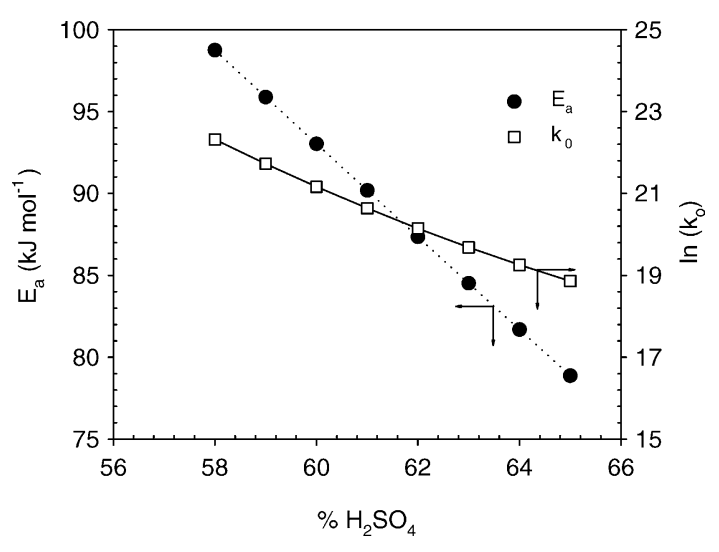

Fig. 2. Kinetic parameters $\left(E_{\mathrm{a}}\right.$ and $\left.k_{\mathrm{o}}\right)$ as function of the sulphuric acid weight fraction.

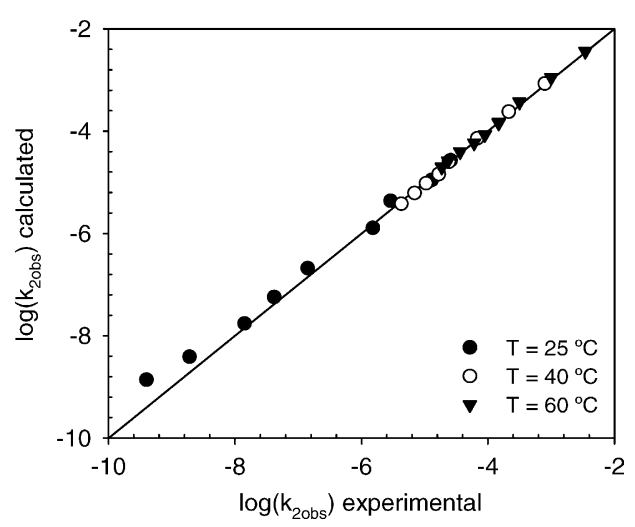

Fig. 3. Parity plot of the experimental (Deno and Stein [26]; Marziano et al. [27]) and calculated values of the $\log k_{2 \text { obs }}$ for the temperatures of 25,40 and $60^{\circ} \mathrm{C}$.

\subsection{The film model}

The film model used to describe a heterogeneous mass transfer enhanced by chemical reaction is fully presented in the literature $[10,11]$. Here, it is illustrated for the case of the benzene heterogeneous nitration. This model is based on the following assumptions: the fluid can be divided into two distinct zones-a stagnant film of thickness $\delta$,

$\delta=\frac{D}{k_{\mathrm{L}}}$

near the interface and a perfectly mixed homogeneous bulk where concentration gradients do not occur; the mass transfer process is at steady state and isothermal.

In Fig. 4, a schematic representation of this model is presented for the benzene nitration, which has as main reaction product the mononitrobenzene (MNB), and where the mass transfer resistances in the organic phase are neglected. Using the film model, with a pseudo-first order reaction, a steady state mass balance to the benzene in the film of the aqueous phase leads to

$D \frac{\mathrm{d}^{2} C_{\mathrm{B}, \text { film }}}{\mathrm{d} x^{2}}-k C_{\mathrm{B}, \text { film }}=0$,

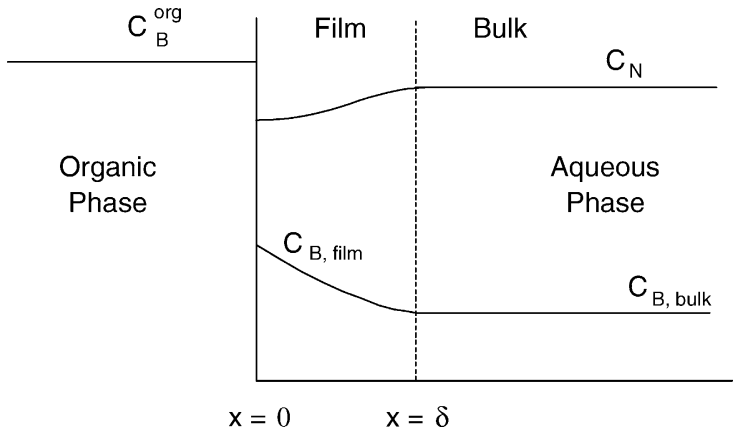

Fig. 4. Schematic representation of the film model for the benzene heterogeneous nitration.

with boundary conditions:

$C_{\mathrm{B}, \mathrm{film}}=C_{\mathrm{B}, \mathrm{film}}(0), \quad x=0$

$C_{\mathrm{B}, \text { film }}=C_{\mathrm{B}, \text { bulk }}, \quad x=\delta$

The solution of this differential equation is given by [11]:

$$
\begin{aligned}
\frac{C_{\mathrm{B}, \text { film }}}{C_{\mathrm{B}, \mathrm{film}}(0)}= & \frac{1}{\sinh (H a)}\left\{\sinh \left[H a-x \sqrt{\frac{k}{D}}\right]\right. \\
& \left.+\frac{C_{\mathrm{B}, \text { bulk }}}{C_{\mathrm{B}, \text { film }}(0)} \sinh \left[x \sqrt{\frac{k}{D}}\right]\right\} \text { for } 0 \leq x \leq \delta
\end{aligned}
$$

The benzene concentration at the interface, $C_{\mathrm{B}}$, film $(0)$, can be obtained by

$C_{\mathrm{B}, \mathrm{film}}(0)=m C_{\mathrm{B}}^{\mathrm{org}}$

using the partition coefficient $m$, as described by Zaldivar et al. [4].

\subsection{Model for the continuous pilot reactor}

The pilot reactor is considered to work as a perfectly mixed continuous reactor (CSTR) and is described in more detail in

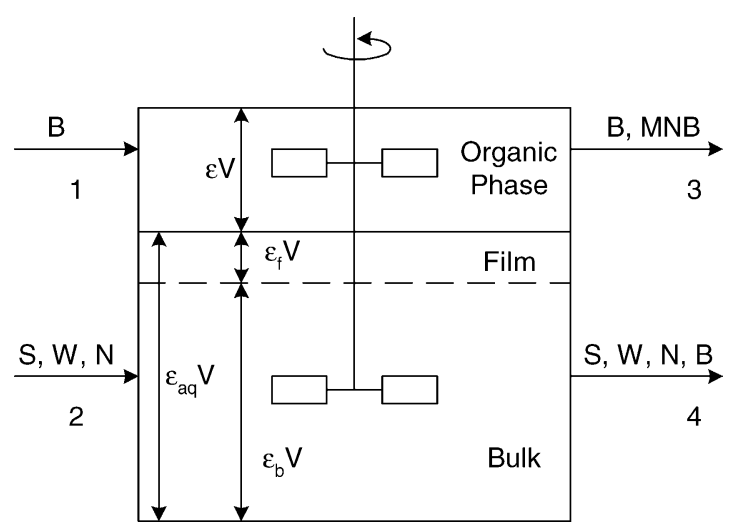

Fig. 5. Schematic representation of the pilot reactor using the film model. 
the experimental section. In Fig. 5, the pilot reactor is represented conceptually using the film model with two different main zones corresponding to the phases present. The organic phase inlet stream (1) contains benzene and the outlet stream (3) contains the reaction product, mononitrobenzene (MNB) and unreacted benzene. In this phase, assumed as perfectly mixed, the benzene concentration is as illustrated in Fig. 4. The second zone represents the aqueous phase, which is divided into the film and the bulk. The bulk is also well mixed without concentration gradients, while the film exhibits a concentration profile according to the model. This model considers the reaction as occurring only in the aqueous phase, both in the film and the bulk; it is considered that under this operating conditions no nitration reaction occur in the organic phase. Several authors refer that some undesired reactions, or even to a small extent the nitration reaction, may occur in the organic phase [28-30]. This may be due to the solubility of the nitric acid in the organic phase, which is higher than the water and the sulphuric acid solubilities [29], leading to the increase of the nitration's by-products formation by oxidation of the unreacted benzene to phenol [31]. The nitric acid may be transferred to the organic phase along with MNB formed, due to its higher solubility in MNB than in benzene [32]. Nevertheless, the maximum rate of nitration in the organic phase is many orders of magnitude less than in the aqueous phase and can be neglected [25,30].

Our aim is to predict the benzene and the MNB concentrations at the reactor outlet, and compare the predicted values with the experimental concentrations measured. For that purpose, the complete reactor mathematical model must include the mass balances to the organic phase and to the film and the bulk of the aqueous phase. Considering that the reaction occurs only in the aqueous phase, the mass balances for benzene in both organic and bulk of aqueous phases at the steady state can be formulated as follows:

Organic phase : $\quad 0=F_{\mathrm{B}}^{\mathrm{org}, \text { in }}-F_{\mathrm{B}}^{\mathrm{org}, \mathrm{out}}-a V J_{\mathrm{B}, x=0}$

Bulk of aqueous phase :

$0=-F_{\mathrm{B}}^{\text {bulk, out }}+a V J_{\mathrm{B}, x=\delta}-k C_{\mathrm{B}, \text { bulk }} \varepsilon_{\mathrm{b}} V$

The linkage between these equations is achieved by calculating the benzene molar flux $\left(J_{\mathrm{B}}\right)$ between phases which, for a given space coordinate $x_{1}$, is given by

$J_{\mathrm{B}, x_{1}}=-D\left(\frac{\mathrm{d} C_{\mathrm{B}, \text { film }}}{\mathrm{d} x}\right)_{x_{1}}$.

The molar flux of benzene across the interface between the organic phase and the aqueous film can be obtained by differentiating Eq. (11) at $x=0$. The molar flux from the stagnant film to the bulk phase can be calculated using the same strategy at $x=\delta$. According to Westerterp et al. [11], the molar flux across the interface from the organic to the aqueous phase $(x=0)$ where a benzene concentration prevails is given by

$J_{\mathrm{B}, x=0}=k_{\mathrm{L}}\left(m C_{\mathrm{B}}^{\mathrm{org}}-\frac{C_{\mathrm{B}, \text { bulk }}}{\cosh (H a)}\right) \frac{H a}{\tanh (H a)}$.

For slow $(\mathrm{Ha}<0.3)$ or fast $(H a>2)$ reactions, the molar flux can be approximated to the following asymptotic expressions, respectively:

$H a<0.3: J_{\mathrm{B}, x=0}=k_{\mathrm{L}}\left(m C_{\mathrm{B}}^{\mathrm{org}}-C_{\mathrm{B}, \text { bulk }}\right)$

$H a>2.0: J_{\mathrm{B}, x=0}=m C_{\mathrm{B}}^{\mathrm{org}} \sqrt{k D}$

This means that for slow reactions the molar flux is independent of both the diffusion coefficient and the kinetic constant, depending only on the mass transfer coefficient, like in a pure mass transfer process with no reaction involved. On the other hand, for fast reactions the molar flux is enhanced by the chemical reaction and is independent of the mass transfer coefficient. Yet, the global reaction rate is always dependent on the effective interfacial area through which the molar flux occurs. For the slow reactions the interfacial area influences only the mass transfer and the rate-limiting step is the reaction that occurs only in the bulk phase. For fast reactions, the organic reactant is exhausted in the aqueous film, and the process is controlled by the mass transfer resistances and influenced by the interfacial area, the diffusion and the kinetic constant and not dependent on the bulk size. In the intermediate regime, $0.3<H a<2$, Eq. (16) must be used to obtain the molar flux at $x=0$.

The simultaneous solution of Eqs. (13) and (14) allows the prediction of the outlet benzene concentration in the organic phase $\left(C_{3 \mathrm{~B}}\right)$, which can be achieved analytically:

$$
\begin{aligned}
0= & Q_{1} C_{1 \mathrm{~B}}-Q_{3} C_{3 \mathrm{~B}}-k_{\mathrm{L}}\left(m C_{3 \mathrm{~B}}-\frac{C_{4 \mathrm{~B}, \text { bulk }}}{\cosh (H a)}\right) \\
& \times \frac{H a}{\tanh (H a)} a V
\end{aligned}
$$

$$
\begin{aligned}
0= & -\frac{\varepsilon_{\mathrm{b}}}{\varepsilon_{\mathrm{aq}}} Q_{4} C_{4 \mathrm{~B}}+\sqrt{D k}\left(\frac{m C_{3 \mathrm{~B}}}{\sinh (H a)}-\frac{C_{4 \mathrm{~B}, \text { bulk }}}{\tanh (H a)}\right) \\
& \times a V-\varepsilon_{\mathrm{b}} k C_{4 \mathrm{~B}, \text { bulk }} V
\end{aligned}
$$

In order to solve the mass balance equations, it is important to quantify the relative volume occupied by the film and the bulk in the aqueous phase. This is accomplished through the Hinterland ratio $(A l)$ defined as the volume ratio between aqueous phase and the film:

$A l=\frac{\varepsilon_{\mathrm{aq}}}{a \delta}=\frac{\varepsilon_{\mathrm{aq}} k_{\mathrm{L}}}{a D}$

This equation can be re-written to evaluate the film holdup fraction

$\varepsilon_{\mathrm{f}}=\frac{\varepsilon_{\mathrm{aq}}}{A l}$ 
and the last equations enables the quantification of the bulk hold-up fraction

$\varepsilon_{\mathrm{b}}=\varepsilon_{\mathrm{aq}} \frac{(A l-1)}{A l}$.

The effective interfacial area is a relevant parameter in two-phase reactions, since it depends not only on the reacting system, its composition and physical properties, but also on the reactor design. Previous work carried out in this pilot plant, for a reacting system identical to the one used in this study, led to [33]:

$a=\frac{1}{\left[1+(0.22 /(W e \varepsilon))^{2}\right]\left(-1.40 \varepsilon^{2}+2.41 \varepsilon\right)}$,

where $\varepsilon$ represents the hold-up fraction of the organic phase and the Weber number ( $\mathrm{We}$ ) depends on the agitation, impeller and physical properties of the liquids involved, such as the aqueous phase density and the interfacial tension between the two liquid phases.

\section{Experimental procedure}

The pilot plant used in this experimental work is described elsewhere [31]. A Teflon continuous flow stirred tank reactor is used to mix the water and the sulphuric and nitric acids streams, to produce the mixed acid. The mixed acid stream passes through a glass/Teflon heat exchanger to control its temperature before entering the main glass/Teflon reactor, where it reacts with benzene. Construction details of the main reactor are given in elsewhere [33], and the operating procedures used in these experiments are described in Quadros et al. [31]. A two-paddle impeller described in Quadros and Baptista [33] was used. The pilot plant reproduces the continuous adiabatic benzene nitration process and every process variable (temperature, residence time, flow rates, stirring speed and reactants level in the feeding tanks) was measured and registered on-line.

A run in the pilot plant consists in setting the flow rates, feed temperatures and stirring speed and waiting until every monitored variable profile becomes stabilised. This corresponds to a steady state in the continuous reactor. After this stage, samples of the reacting mixture and mixed acid were collected. The stirring speed is then changed to a new set point to obtain a new set of data. The procedures used during the run, as well as to handle samples are described in previous studies [31]. The samples collected were separated and prepared for analysis. The acid phase was titrated against solutions of $1 \mathrm{M}$ sodium hydroxide and iron sulphate to determine the total acidity and the nitric acid concentration, respectively. The organic phase was diluted in methanol and analysed by GC, using a silica gel DB-1 J \& W column.

In order to reproduce the industrial conditions, a sulphuric acid strength of $68 \%(\mathrm{wt})$, free from nitric acid, and a residence time of $2 \mathrm{~min}$ had been used in every run. Other important operating parameters were the molar feed ratio between the benzene and the nitric acid $\left(F_{\mathrm{B}} / F_{\mathrm{N}}\right)$, the temperature of the mixed acid ( $\left.T_{\text {mixed acid }}\right)$, the nitration temperature ( $\left.T_{\text {nitration }}\right)$, the stirring speed $(N)$, the hold-up fraction $(\varepsilon)$, the feed ratio between the volumetric flow rates of the aqueous phase and the organic phase $\left(Q_{\mathrm{aq}} / Q_{\mathrm{org}}\right)$ and the weight fraction of the nitric acid in the mixed acid. These operating conditions are summarized in Table 1 . The process is adiabatic, within experimental accuracy. The benzene is fed at room temperature in every run. This explains why, for low stirring speed and small reaction extension, the nitration temperature is lower than the mixed acid temperature. Although in industrial practice, an excess of benzene is used with a molar feed ratio $F_{\mathrm{B}} / F_{\mathrm{N}}$ in between 1.06 and 1.08 , here this ratio was tested further in the range from 0.96 to 1.15. The volumetric ratio between phases is close to 8 , which is normally a reference value in industrial adiabatic nitrations.

It is important to mention that the $68 \%$ sulphuric acid strength usually reported in the industrial process refers to the initial concentration in the sulphuric acid feed, which is free from nitric acid. The mixed acid formation decreases this concentration leading to a nitric acid concentration of approximately $5 \%$ and a sulphuric acid concentration about $57-58 \%$ in the mixed acid stream. The sulphuric acid concentration inside the reactor ranges from 58 to $63 \%$, according to the conversion of nitric acid that leads to a decrease in the total acidity by water formation, increasing however the weight fraction of the sulphuric acid.

The nitration temperature used in these experiments $\left(80-135^{\circ} \mathrm{C}\right)$ was much higher than in previous studies reported in the literature carried out below $40^{\circ} \mathrm{C}[4,5]$. This enabled to gather information in the range of temperature used in aromatic nitration plants.

Table 1

Operating conditions used in the experimental runs

\begin{tabular}{llllllll}
\hline Run & $F_{\mathrm{B}} / F_{\mathrm{N}}$ & $T_{\text {mixed acid }}\left({ }^{\circ} \mathrm{C}\right)$ & $T_{\text {nitration }}\left({ }^{\circ} \mathrm{C}\right)$ & Stirring speed $(\mathrm{rpm})$ & $\varepsilon$ & $0.132-0.169$ & 8.43 \\
\hline 1 & 0.96 & 99.7 & $94.6-121.7$ & $398-895$ & $0.130-0.169$ & 8.38 & $\mathrm{HNO}_{3}(\mathrm{wt} \%)$ \\
2 & 0.98 & 89.5 & $85.7-113.2$ & $395-911$ & $0.130-0.170$ & 8.11 & 5.64 \\
3 & 1.07 & 102.6 & $96.2-135.3$ & $394-1700$ & $0.142-0.172$ & 8.09 & 4.99 \\
4 & 1.07 & 88.9 & $85.2-121.2$ & $396-1342$ & $0.156-0.171$ & 8.09 & 5.10 \\
5 & 1.09 & 81.3 & $99.1-114.3$ & $858-1381$ & $0.131-0.175$ & 7.86 & 5.97 \\
6 & 1.10 & 84.8 & $81.1-111.4$ & $398-885$ & $0.132-0.180$ & 7.75 & 5.29 \\
7 & 1.15 & 90.2 & $86.2-117.2$ & $394-870$ & \\
\hline
\end{tabular}




\section{Results and discussion}

In the range of reaction temperature and sulphuric acid strength used in industrial adiabatic nitrations, and tested in this study, the results reveal that the production of MNB is highly dependent on the stirring speed as illustrated in Fig. 6. In a recent paper, Quadros and Baptista [33] studied the influence of the stirring speed upon interfacial area formation. Eq. (24), which relates the effective interfacial area to stirring speed, was used to build Fig. 7, using data from run 4. Figs. 6 and 7, which correspond to the same run, support the relevance of interfacial area on this liquid-liquid reaction dependent on mass transfer. The shape of the three curves in these figures emphasises their interdependence in this adiabatic process; as interfacial area increases the extent of reaction augments and produces a temperature increase. A similar trend when studying the influence of stirring speed has been registered by other authors $[8,30]$ in their isothermal experiments with CSTR's at lower temperatures.

The first step on the use of a process model to correlate these experimental results is to find the reaction regime where the reaction occurs, i.e. slow, intermediary, fast or instanta-

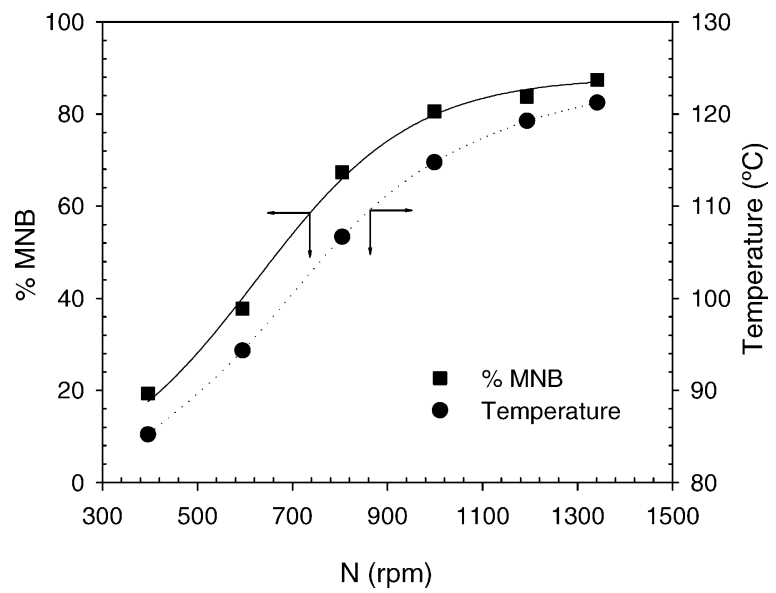

Fig. 6. Temperature and MNB production profiles vs. stirring speed, run 4.

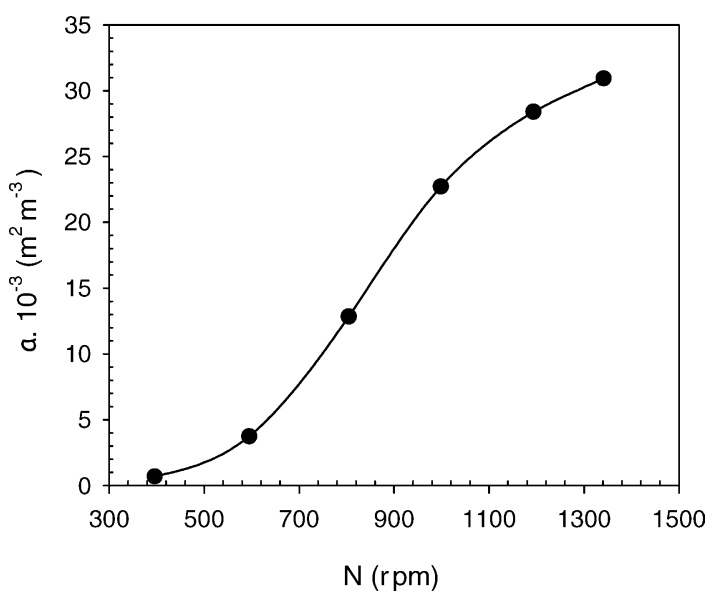

Fig. 7. Effective interfacial area vs. stirring speed, run 4.

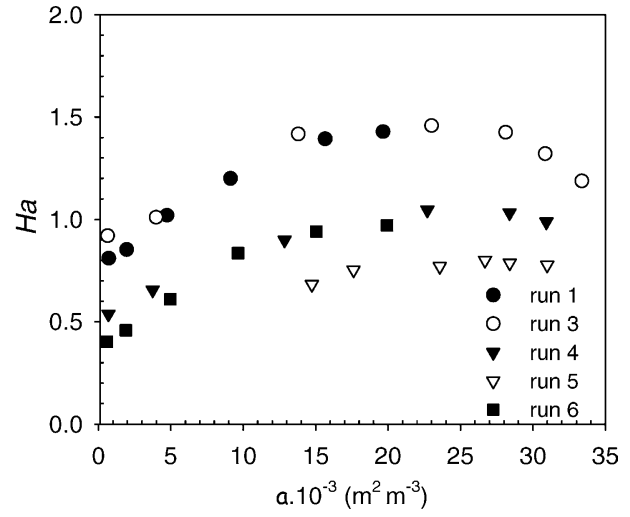

Fig. 8. The Hatta number registered at different effective interfacial areas, runs $13,4,5$ and 6.

neous reaction. The parameter used to describe the reaction regime is the Hatta number in Eq. (1) where the $k$ constant for this pseudo-first order reaction is given by $k=k_{20 b s} C_{\mathrm{HNO}_{3}}$. For every experimental run in this study the Hatta number was comprised between 0.3 and 2, as illustrated in Fig. 8, which corresponds to the intermediate regime where both mass transfer and kinetic parameters interfere with the global reaction rate. To improve clearness not every run is represented in Fig. 8 but it is important to register that in some runs a maximum value of $\mathrm{Ha}$ occurs for a given interfacial area, which is not the maximum area attained in the run. Since the Hatta number is proportional to the square root of nitric acid concentration and a larger interfacial area increases the reaction rate consuming more nitric acid, the pattern in Fig. 8 is explained. Nevertheless, this drop on $\mathrm{Ha}$ is not followed by a decrease in the MNB production, as illustrated in Fig. 9, where the MNB concentration increases steadily even when $H a$ decreases, as happens in runs 3, 4 and 5. From these figures, it is possible to confirm that the MNB production is not only dependent on the $\mathrm{Ha}$ number, since for higher $\mathrm{Ha}$ a lower MNB production can be attained as registered in run 1, particularly when lower interfacial areas are used. The higher Hatta numbers in run 1 are a consequence of nitric acid excess relative to benzene, which increases $H a$, but does not dispose enough benzene in the aqueous phase for reaction.

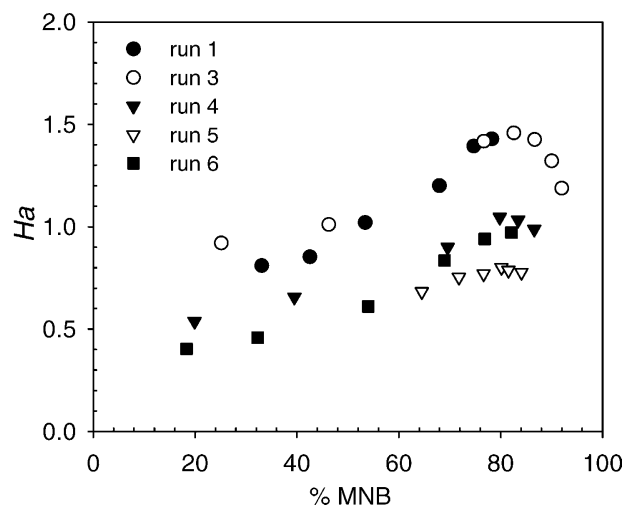

Fig. 9. MNB production vs. $H a$, runs 1, 3, 4, 5 and 6. 


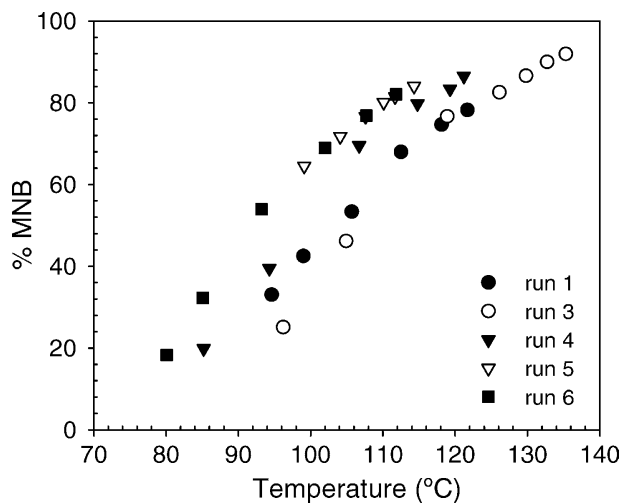

Fig. 10. MNB production at different nitration temperatures, runs 1, 3, 4, 5 and 6.

On the other hand, the range of $\mathrm{Ha}$ in run 3 reflects the nitration temperature and the stirring speed used. A high Hatta number can also be related to a high nitration temperature, since an increase in temperature causes a significant increase in the kinetic constant. However, if the interfacial area and the benzene amount available are smaller than in lower temperature experiments, it will not lead to an increase in the overall reaction rate. This reveals a close relation between the reaction temperature and the MNB production as highlighted in Fig. 6 and registered in Fig. 10. In Fig. 10, it is possible to observe that, for the same reaction temperature, different MNB productions are obtained. These differences can be due to the interfacial area available for reaction that improves conversion and heat production. Moreover, the mixed acid feed stream temperature must contribute to this pattern as well, since different temperatures of the mixed acid lead to different reaction temperatures. This is an important remark since it will allow optimising the reaction temperature in order to achieve the same productivity, with energy savings and selectivity improvements [31]. However, these are not the only parameters that affect the MNB production. For the same temperature, an increase in MNB formation is noticed in the runs with a higher $F_{\mathrm{B}} / F_{\mathrm{N}}$ ratio. This parameter together with the interfacial area can lead to a high increase in benzene conversion, even if the reaction temperature is decreased and, by arranging these parameters, the conventional industrial adiabatic nitration process can be optimised with important by-products reduction [34].

In the range of Hatta number used, it is assumed that the benzene reacts in the film and in the bulk of the aqueous phase. The mathematical model for this system using the intermediate regime (Eqs. (19) and (20)) was used to calculate the benzene outlet stream concentration. For a particular run (5) and for each stirring speed these results are plotted in Fig. 11, together with the experimental data. A very good agreement between the experimental and the predicted results is obtained, confirming the adequacy of this model to describe the reaction and transport processes involved in the benzene nitration in the range of operating conditions used. The model results when assuming fast and slow reaction regimes are also

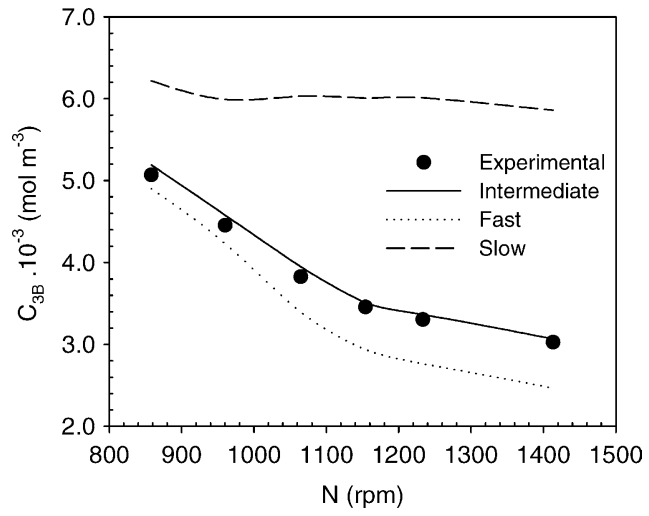

Fig. 11. Experimental and predicted values for benzene concentration in the outlet stream as function of stirring speed, run 5 . The film model concentration profiles: fast, intermediate and slow reaction regime.

represented in Fig. 11. It can be observed that the predictions of these limit regimes clearly deviate from the experimental data, especially for the case of the slow reaction regime. Moreover, these results prove that, although benzene nitration under industrial operating conditions is usually considered as a fast reaction limited by the diffusion resistances and modelled thereafter, this may not be the most correct assumption. For the fast and the intermediate regimes, where mass transfer resistances are relevant, the pattern of the outlet benzene concentration in Fig. 11 is clearly dependent on increasing stirring speed, especially in the lower stirring speed range, while a gentle slope is registered for higher stirring speeds. This is in full agreement with the pattern of interfacial area versus stirring speed in Fig. 7. For the slow reaction regime, the limiting step is the chemical reaction and the interfacial area is not so influential as registered in Fig. 11.

In this model, it is assumed that the MNB produced is instantaneously transferred to the organic phase. However, according to the literature [32] this compound is more soluble in the aqueous phase than benzene. Therefore, it is interesting to check the model by confronting experimental and model predictions for MNB weight percentage in the organic phase of the outlet stream. This is achieved in Fig. 12 where the

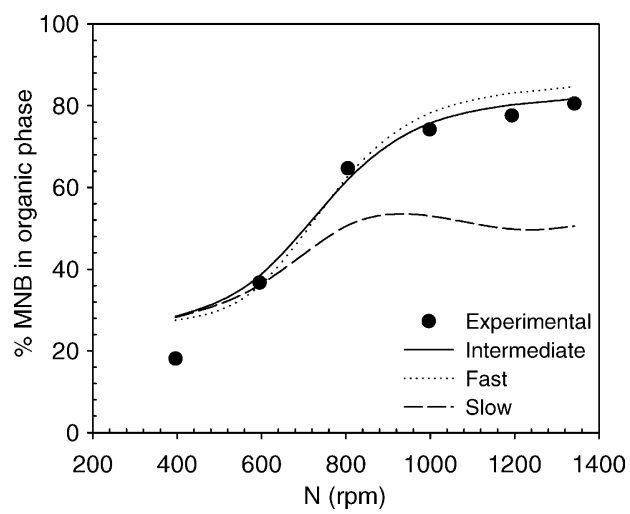

Fig. 12. Experimental and predicted values for wt $\% \mathrm{MBN}$ in the organic phase in the outlet stream as function of stirring speed, run 4 . The film model prediction profiles: fast, intermediate and slow reaction regime. 


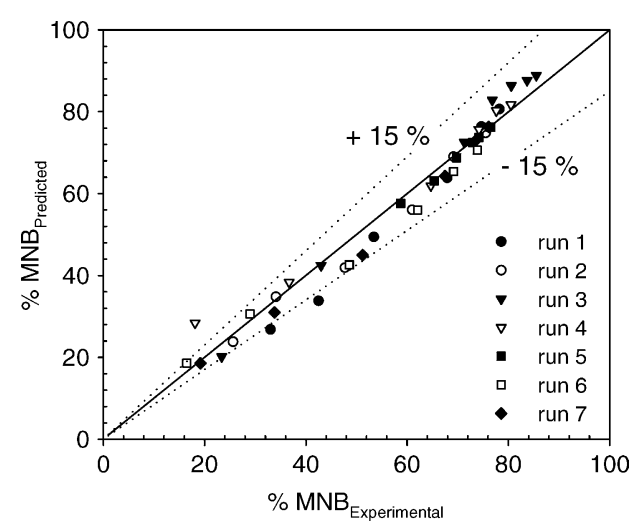

Fig. 13. Experimental vs. predicted values of MNB in the organic phase of the outlet stream for every experimental runs.

weight percentage of MNB is plotted against stirring speed for different reaction regimes, including the experimental results. Once again, a very good match is achieved between experimental and model results and the intermediate regime is adequate for the operating conditions tested. In Fig. 12, which illustrates run 4 results, the differences between the intermediate and fast regimes are not so outstanding as in Fig. 11. The Hatta numbers in run 4 are also higher than in run 5 represented in Fig. 11 (see Fig. 9), and therefore, closer to the asymptotic solution that corresponds to a fast reaction. In the lower stirring speed range every model predicts almost the same MNB content in the organic phase, which, for this particular run, does not correspond to the experimental value. However, in these lower stirring speed ranges, where the turbulent flow regime is not fully developed, the interfacial area estimation is more difficult, as reported in literature [33] and this may explain these differences. Nevertheless, Fig. 13 reveals that this may be just a less accurate experimental value. As Fig. 13 shows, for every run the MNB content is estimated with less than $15 \%$ error. This can be considered remarkable, having in mind that in this model a great number of parameters have been estimated and several correlations used, such as mass transfer and diffusion coefficients, kinetic constants, solubilities, power input and effective interfacial area, among others.

According to the film theory, in the intermediate regime, part of the reaction occurs in the film, while the other is carried out in the well-mixed bulk. Since the stirring speed, by means of the effective interfacial area, plays an important role in the film and bulk dimensions, it is important to increase the film/bulk volume ratio when the reaction starts to be faster. It is interesting to analyse the film and bulk hold-up fractions as functions of the stirring speed in the reactor, using the Hinterland ratio and Eqs. (22) and (23). Fig. 14 registers the variation of the different hold-up fractions in the reactor, for run 7 . The organic and aqueous hold-up fractions can be considered as independent of the stirring speed. However, due to the fact that the molecules of MNB produced have a bigger size than the benzene molecules, while on the other hand the nitric acid molecules consumed are bigger than the water

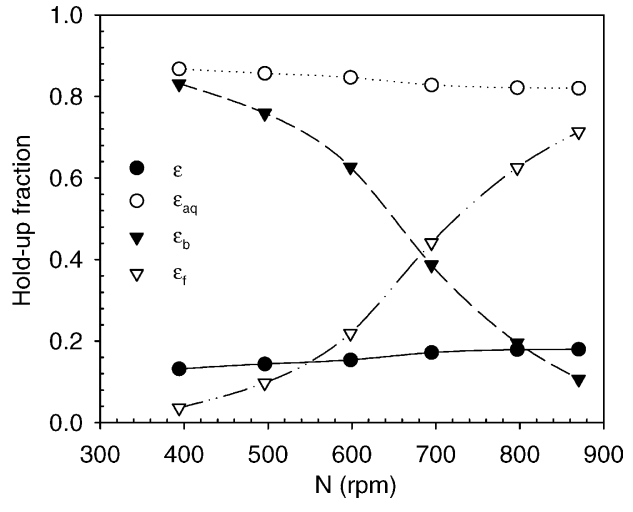

Fig. 14. Hold-up fractions of the organic and aqueous phase and bulk and film aqueous phase vs. the stirring speed, run 7 .

molecules produced, the organic and aqueous phase hold-up fractions register small changes due to increase in process conversion, which is augmented by the stirring speed. The same is not true for the film and bulk hold-ups. In this case, for the lower stirring speeds where small interfacial areas prevail, the hold-up fraction of the film is very small and most of the volume of the aqueous phase is in the bulk. However, when the stirring speed and the interfacial area increase an inversion on the size of these hold-ups occurs. The film hold-up becomes much larger than the bulk, leaving much more active places for the reaction to occur. To reinforce that by increasing stirring speed the reaction takes place mostly in the film, it seems important to quantify the percentage of benzene converted in the film phase, which is represented in Fig. 15 for run 7. Even for the lower stirring speeds, where the hold-up fraction of film is small, the percentage of benzene converted in the film assumes values higher than $20 \%$. The amount of reaction occurring in the film increases very fast with stirring speed, achieving values around $90 \%$ for stirring speeds close to $900 \mathrm{rpm}$, where the volume of film is more significant compared to the bulk volume. It is interesting to reiterate again in Fig. 15 the close relationship between the amount of benzene converted in the film and the effective

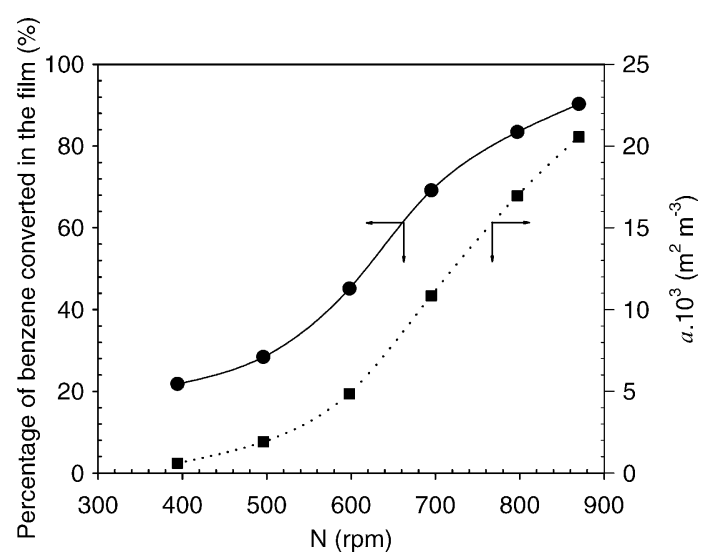

Fig. 15. Percentage of benzene converted in the aqueous film and effective interfacial area vs. stirring speed, run 7. 
interfacial area, which reinforces the importance of correct interfacial area quantification.

\section{Conclusions}

An experimental study of the continuous adiabatic benzene nitration with mixed acid was conducted in a pilot plant to reproduce the industrial data and to produce results for modelling this heterogeneous reaction using the film model. Different sets of operating conditions were tested, with special emphasis on the stirring speed, temperature of feed stream and reaction, flow rates, reactants ratio and hold-up fraction. The results show a strong dependence of the reaction on the effective interfacial area, temperature and feed ratio. The film model was used to describe the reaction that, for the conditions tested, occurs in the intermediate regime and the results were compared with the asymptotic solutions for slow and fast reactions, confirming that the intermediate regime leads to the best results. Both the concentrations of benzene and MNB predicted by the model were confronted with the experimental results and an extremely good agreement was registered. The observed second order kinetic rate constant for the benzene nitration was related to the sulphuric acid strength making use of results obtained by previous authors, which proved to be a good strategy. These experiments and modelling work led to a better understanding of the adiabatic benzene nitration process using operating conditions close the ones used in industry. Moreover, by establishing the reaction regime, according to the Hatta number, a relevant contribution has been achieved, which can be very useful for the optimisation and design of this industrial process, not fully established.

The results reported here were obtained for fixed residence time and sulphuric concentration. Nevertheless, it is our aim to study these parameters in the future, as well as to make use of other mathematical models to enable a complete process optimisation.

\section{Acknowledgements}

Financial support from Fundação para a Ciência e Tecnologia (FCT), for the Ph.D. grant SFRH/BD/1266/2000 and from Quimigal S.A., Portugal is gratefully acknowledged. We wish to thank the assistance in the experimental work of Engineers Alzira Vilaboa, Catarina Viana and Raquel Costa.This work is dedicated to the memory of Professor José Almiro e Castro.

\section{References}

[1] E.D. Hughes, C.K. Ingold, R.I. Reed, Kinetics and mechanisms of aromatic nitration. Part II. Nitration by the nitronium ion, $\mathrm{NO}_{2}{ }^{+}$, derived from nitric acid, J. Chem. Soc. (1950) 2400-2473.
[2] G.A. Olah, R. Malhotra, S.C. Narang, Nitration: Methods and Mechanisms, VCH publishers, New York, 1989.

[3] P.R. Cox, A.N. Strachan, Two-phase nitration of toluene (part II), Chem. Eng. J. 4 (1972) 253-261.

[4] J.M. Zaldivar, E. Molga, M.A. Alós, H. Hernández, K.R. Westerterp, Aromatic nitrations by mixed acid. Slow liquid-liquid reaction regime, Chem. Eng. Process. 34 (1995) 543-559.

[5] J.M. Zaldivar, E. Molga, M.A. Alós, H. Hernández, K.R. Westerterp, Aromatic nitrations by mixed acid. Fast liquid-liquid reaction regime, Chem. Eng. Process. 35 (2) (1996) 91-105.

[6] R.D. Biggs, R.R. White, Rate of nitration of benzene with mixed acid, AIChE J. 2 (1) (1956) 26-33.

[7] H.M. Brennecke, K.A. Kobe, Mixed acid nitration of toluene, Ind. Eng. Chem. 48 (8) (1956) 1298-1304.

[8] C. Hanson, J.G. Marsland, G. Wilson, Macrokinetics of toluene nitration, Chem. Eng. Sci. 26 (1971) 1513-1520.

[9] P.V. Danckwerts, Gas-Liquid Reactions, McGraw-Hill Book Company, 1970.

[10] L.K. Doraiswamy, M.M. Sharma, Heterogeneous reactions: analysis examples and reactor design, vol. 2, John Wiley \& Sons, 1984.

[11] K.R. Westerterp, W.P.M. Van Swaaij, A.A.C.M. Beenackers, Chemical Reactor Design and Operation, John Wiley \& Sons, 1990.

[12] J.W. Chapman, A.N. Strachan, Two phase nitration of clorobenzene in 79.8\% sulphuric acid, in: L.F. Alright, C. Hanson (Eds.), Industrial and Laboratorial Nitrations, 22, ACS Symposium series, 1976, pp. 219-224.

[13] L.R. Perkins, C.J. Geankoplis, Molecular diffusion in a ternary liquid system with the diffusing component dilute, Chem. Eng. Sci. 24 (1969) 1035-1042.

[14] P.H. Calderbank, M.B. Moo-Young, The continuous phase heat and mass-transfer properties of dispersions, Chem. Eng. Sci. 16 (1961) $39-54$.

[15] B.A.A. van-Woezik, K.R. Westerterp, Measurement of interfacial areas with the chemical method for a system with alternating dispersed phases, Chem. Eng. Process. 39 (4) (2000) 299-314.

[16] D.S. Azbel, N.P. Cheremisinoff, Fluid Mechanics and Unit Operations, Ann Arbor Science Publishers, Michigan, 1983

[17] C. Roizard, G. Wild, Mass transfer with chemical reaction: the slow reaction regime revisited, Chem. Eng. Sci. 57 (2002) 3479-3484.

[18] H. Benbelkacem, H. Debellefontain, Modeling of a gas-liquid reactor in batch conditions. Study of the intermediate regime when part of the reaction occurs within the film and part within the bulk, Chem. Eng. Process. 42 (2003) 723-732.

[19] F.A. D'Angelo, L. Brunet, P. Cognet, M. Cabassud, Modelling and constraint optimisation of an aromatic nitration in liquid-liquid medium, Chem. Eng. J. 91 (2003) 75-84

[20] C. Hanson, M.W.T. Pratt, M. Sohrabi, Some aspects of aromatic nitration in aqueous systems, in: L.F. Albright, C. Hanson (Eds.), Industrial and Laboratorial Nitrations, 22, ACS Symposium Series, Washington, 1976, pp. 225-242.

[21] H.G.M. Edwards, V. Fawcett, Quantitative Raman spectroscopic studies of nitronium ion concentrations in mixtures of sulphuric and nitric acids, J. Mol. Struct. 326 (1994) 131-143.

[22] A.A. Guenkel, J.M. Rae, E.G. Hauptmann, Nitration process, US Patent 5,313,009, 1994.

[23] A.A. Guenkel, T.W. Maloney, Recent advances in the technology of mononitrobenzene manufacture, in: R.V. Carr, R.J. Schmitt, L.F. Albright (Eds.), Nitration: Recent laboratorial and Industrial Developments, ACS Symposium Series, Washington, 1996, pp. 223-233.

[24] R.G. Coombes, R.B. Moodie, K. Schofield, Electrophilic aromatic substitution. Part I. The nitration of some reactive aromatic compounds in concentrated sulphuric and perchloric acids, J. Chem. Soc. B (1968) 800-804.

[25] P.R. Cox, A.N. Strachan, Two-phase nitration of clorobenzene, Chem. Eng. Sci. 26 (1971) 1013-1018.

[26] N.C. Deno, R. Stein, Carbonium ions. III. Aromatic nitration and the $C_{\mathrm{o}}$ acidity function, J. Am. Chem. Soc. 78 (1956) 578-581. 
[27] N.C. Marziano, A. Tomasin, C. Tortato, J.M. Zaldivar, Thermodynamic nitration rates of aromatic compounds. Part 4. Temperature dependence in sulphuric acid of $\mathrm{HNO}_{3} \rightarrow \mathrm{NO}_{2}{ }^{+}$equilibrium, nitration rates and acidic properties of the solvent, J. Chem. Soc. Perkin Trans. 2 (1998) 1973-1982.

[28] A.J. Barduhn, K.A. Kobe, Toluene nitration kinetics, Ind. Eng. Chem. 48 (1956) 1305-1315.

[29] L.F. Albright, D.F. Schiefferle, C. Hanson, Reactions occurring in the organic phase during aromatic nitrations, J. Appl. Chem. Biotechnol. 26 (1976) 522-525.

[30] J. Giles, C. Hanson, H.A.M. Ismail, A model for rate of nitration of toluene under heterogeneous conditions, in: L.F. Alright, C. Hanson (Eds.), Industrial and Laboratorial Nitrations, 22, ACS Symposium Series, 1976, pp. 190-209.
[31] P.A. Quadros, J.A.A.M. Castro, C.M.S.G. Baptista, Nitrophenols reduction in the benzene adiabatic nitration process, Ind. Eng. Chem. Res. 43 (15) (2004) 4438-4445.

[32] D.F. Schiefferle, C. Hanson, L.F. Albright, Heterogeneous nitration of benzene, in: L.F. Albright, C. Hanson (Eds.), Industrial and Laboratorial Nitrations, 22, ACS Symposium Series, Washington, 1976, pp. 176-189.

[33] P.A. Quadros, C.M.S.G. Baptista, Effective interfacial area in agitated liquid-liquid continuous reactors, Chem. Eng. Sci. 58 (17) (2003) 3935-3945.

[34] P.A. Quadros, C.M.S.G. Baptista, Pollution prevention by nitrophenols reduction in the benzene nitration process, in: Proceedings of the Fourth European Conference in Chemical Engineering, Topic 3.3, Granada, Spain, 21-25 September, 2003. 